\title{
A model and prototype implementation for tracking and tracing agricultural batch products along the food chain
}

\author{
L. Ruiz-Garcia ${ }^{\mathrm{a}, *}$, G. Steinberger ${ }^{\mathrm{b}}$, M. Rothmund ${ }^{\mathrm{c}}$ \\ a Laboratorio de Propiedades Físicas y Tecnologías Avalzadas en Agroalimentación. Universidad Politécnica de Madrid, Avda, Compintense s/n 28040 Madizd, Spain \\ ${ }^{b}$ Department of Life Science Engineering. Crop Production Engineering, Center of Life Sciences Weihenstephon. Technische Universität München (TUM), Am \\ Staudenganen 2, D-85354 Freising, Germany \\ COSB AC KTenzestraße 38, 80469 München, Germany
}

Keywords:

Traceability

Web service

Monitoring logistics

IT-farming

Automated documentation

\begin{abstract}
A B S T R A C T
There is an increasing demand of traceability in the food chain, statutory requirements are growing stricter and there is increasing pressure to develop standardized traceability systems. Each event in the chain, like production of transportation, packing, distribution or processing results in a different product which can have its own information associated within the tracing system. From the raw material to the sale of goods, more and more information needs to be gathered and made available. Supplementary information may also be collected at any step, in order to provide data for analysis and optimization of production practices.

Using web-based systems for data processing, storage and transfer makes possible a flexible way of information access, networking and usability. In this paper an architectural proposal is presented and the proposed solution is tested by the implementation of a prototype. The software architecture presented makes use of a series of standards than ofter new possibilities in traceability control and management. For testing the prototype, information from precision farming together with the information recorded during the transport and delivery was used. The system enables full traceability and it complies with all existing traceability standards.
\end{abstract}

\section{Introduction}

\subsection{The importonce of craceability}

Traceability is a main requirement in agrofood and has become an important issue. Traceability facilitates the withdrawal of foods and enables for all the operators of the supply chain to be provided with targeted and accurate information concerning implicated products (Beulens, Broens, Folstar, \& Hofstede, 2005; Sarig, 2003).

Achieving traceability through the end-to-end supply chain is complex; several players are involved, which all need to have access to a reliable data trace. Producers, retailers, authorities and consumers need to be able to trace back and to authenticate food products and raw materials used for food production to comply with legislation and to meet the food safety and food quality requirements. Tracing all components of food offered from "farm to fork", including accurate real time data, allows minimizing food safety risks, achieving a fast and effective response to incidents and increasing confidence in food products (Bechini, Cimino, Marcello- ni, \& Tomasi, 2007; Clapp, 2002; Regattieri, Gamberi, \& Manzini, 2007).

Codex Alimentarius Commission (1999) defined traceability as the "ability to trace the history, application or location of an entity by means of recorded identifications". Regulation EC (European Commission) No. 178/2002, defines traceability as the: "obility to rrace and follow o food, feed, food-producing animal or substance intended to be, or expected to be incorporated into a food or feed, through oll stages of production, processing and distribution" (European Commission, 2002). Traceability involves managing the successive links between batches and logistic units throughout the entire supply chain.

\subsection{Policy requirements}

Global food safety policies have been stipulated by Governmental authorities and a new series of regulations were created and adopted all over the World, with particular incidence in the EU (European Union) and the United States of America (USA), as a consequence of several food incidents and scandals.

According to the actual regulation in the European Union (applicable since 2005), traceability is required in all stages of the supply chain, covering all food and feed as well as business 
operators without prejudice to existing legislation on specific sectors such as beef, fish, GMOs (genetically modified organisms), etc. A food business operator must register and keep information such as: (1) name, address of supplier, nature of products which were supplied from him, also, (2) name, address of customer, nature of products that were delivered to that customer and (3) date of transaction/delivery. Also, there is additional information which is highly recommended to be kept: volume or quantity, batch number and a more detailed description of the product. Unless specific provisions for further traceability exist, the requirement for traceability is limited to ensuring that businesses are at least able to identify the immediate supplier of a product as well as immediate subsequent recipient, with the exemption of retailers to final consumers (European Commission, 2002, 2004).

As in the same way as the aforementioned EU regulation, in the USA, the Bioterrorism Act 2002 calls for one-up/one-down traceability for each link in the supply chain. This regulation requires that each company in the supply chain keeps information about the company that they received the products from, the company who delivered the product to them, the company who took it away, and the company they gave the products to.

ISO (International Standards Organization) ISO/DIS 22005, focus on the same approach to traceability ("one-step-up/one-stepdown", giving the principles and specifies the basic requirements for the design and implementation of a feed and food traceability system (ISO 22005, 2007).

Thus, the need for a common language of information; a standardization of data that will simplify not only tracking and tracing but inventory control, shipping and receiving, and all of the business operations along the supply chain.

\subsection{Development of traceability systems}

A dependable traceability system is based on procedures that ensure all requested information is recorded, and all the recorded information is an accurate and clear reflection of the productive process, being a useful tool in any food company. Traceability and food safety management systems can work properly based on pen and paper versions but they are time and resource consuming which makes them difficult to implement in small and medium sized companies where the resources are scarce (Wang \& Li, 2006).

For true whole-chain traceability, products must be uniquely identified and recorded at each stage of its possession or transformation and these identifiers must be linked if they are to be of value in both traceability and day-to-day operations. Effective traceability requires standardizing the information that needs to be recorded through each step of the food production and distribution chain. In order to achieve traceability across the supply chain, all trading partners must achieve internal and external traceability. If one of the partners in the chain fails to manage these links in either an upstream or downstream sense, the resulting situation is known as a rupture in (or loss of) traceability (Regattieri et al., 2007).

Recent developments in technology offer new features now achievable. These include: advanced data handling systems based on RFID (radio frequency identification) and WSN (wireless sensor networks), precise and informed crop management, operational and recording systems arising from the concept of 'Precision agriculture' (Auernhammer, 2002), the availability of transport information management and decision support systems (Regattieri et al., 2007).

Each event in the chain, like production of transportation, packing, distribution or processing results in a different product which can have its own information associated within the tracing system. From the raw material to the sale of goods, more and more information needs to be gathered and made available. Supplementary information may also be collected at any step, in order to provide data for analysis and optimization of production practices (Thompson, Sylvia, \& Morrissy, 2005).

Kim, Fox, and Gruninger (1995) established three issues most crucial to the success of any traceability system: (1) compatibility, (2) data standardization and (3) definition of a traceable resource unit (TRU). In the last years, the development of traceability systems in food supply chains has been studied by several authors: Van Dorp, 2004 proposed a reference-data model for tracking and tracing food products in supply chains. The model was evaluated by an analysis of the requirements specified for three companies involved in egg production (consumer, grower and breeder). Dupuy, Botta-genoulaz, and Guinet (2002) and Dupuy et al. (2005) used the concept of TRU in order to optimize the minimum batch size in a traceability system. The mixing of production batches was controlled in order to limit the size; developing a mathematical batch dispersion model tested with LINGO software. Folinas, Manikas, and Manos (2006) introduced a framework for the management of traceability data, in fresh, non-processed food products supply chains. The model was based in eXtensible Markup Language (XML) Schemas technology. Bollen, Riden, and Cox (2007) and Riden and Bollen (2007), studied and analyzed the traceability in fruit supply chains in order to improve the traceability control of the batches, concluding that there is potential to implement high precision and fine granularity traceability in agricultural supply systems, which can also meet a number of other

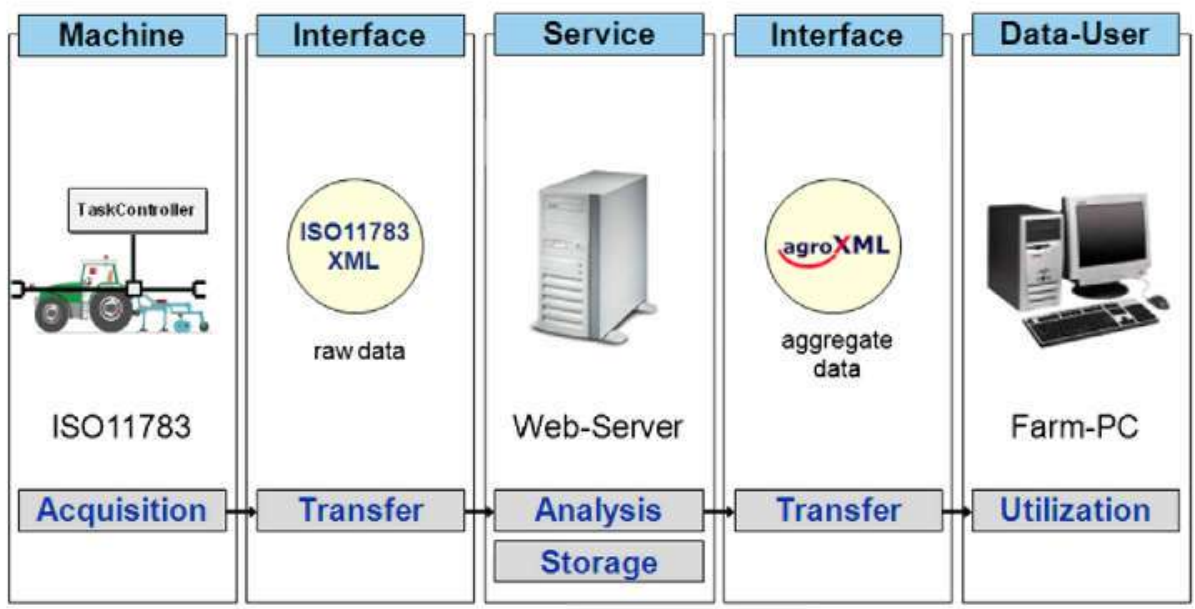

Fig. 1. Agricultural Process Data Service (Steinberger et al., 2006), 
purposes such as improved feedback to producers and benefits to supply system efficiency, as well as being acceptable for compliance purposes. Serrano, Jiménez-Hornero, Gutjêrrez de Ravé, and Jodral (2008) show how georreferenced data from Geographical Information Systems (GIS) can improve the traceability control of high quality honey, creating a open source code-based GIS web site was which fulfills the needs of characterizing the honeys.

\subsection{Precision forning and traceability}

The chain, from harvest to the consumer's plate, forms a single entity. Auernhammer (2002) defined the role of precision agriculture in crop product traceability. Showing how the documentation of production using advanced electronic equipment сал provide valuable information for knowing the complete history of the products.

Nowadays we have more precise and informed crop and animal production management, operational and recording systems. Transpareлсу is gained for the purpose of quality assurance, knowing for example which fertilizer was spread and when, and which pesticides or insecticides were used. In this context, automated process data acquisition systems have веeл developed on the basis of the ISO11783 standard (ISOBUS) in mobile farm equipment (Auernhammer, Spangler, \& Demmel, 2000) and also in robots for agriculture linked with traceability systems (Arima, Kondo, Shibusawa, \& Yamashita, 2003).

Managing and processing the huge amount of data, and provide useful information, it is a challenge that has been answered by developing and using a server based data management system controlled by web-based user interfaces (Rothmund \& Auernhammer, 2004). In a next step the process data base has веeл embedded in a web service environment following $0 G C$ standards (Fig. 1). This "Agricultural process data service" can deliver the information basis of raw material production and was developed іл framework from the research project Preagro (Steinberger, Rothmund, \& Auernhammer, 2006). The aim of this project was to develop a management system for site specific crop production, in order to increase the profitability of agriculture and to enhance the beлеfits for the елviroлmeлt (Ртеagro, 2008).

\subsection{Monitoring logistics and traceability}

A complex factor is the addition of new product information that occurs as the product moves through the food chain. A traceability system must trace both products and activities (Moe 1998; Thompson et al., 2005). In the case of traceability for perishable food products, monitoring logistics is of particular interest for the companies; because the major challenge is to ensure a continuous cold chain from producer to consumer in order to guaranty prime conditions of goods (Coulomb, 2005; Ruiz-Garcia, Barreiro, Rodríguez-Bermejo, \& Robla, 2007).

Recent developments in food logistics allow monitoring transport and distribution of food products by means of sensor networks, wired or wireless, and GNSS (global navigation satellite systems) based tracking devices. The most effective way for the food company to prove that a third-party transport has done its job correctly is to monitor the shipment independently from the transport company. Jedermann, Behrens, Westphal, and Lang (2006) and Ruiz-Garcia et al. (2007) and Ruiz-Garcia and Barreiro (2008) have studied monitoring transport systems by means of WSN and RFID. These systems automatically and continually collects data such temperature, humidity, location, status of cooling equipment, light, etc. Hsu, Chen, and Wang (2008) developed a RFID-enabled traceability system for the logistic of live fish, integrating the information іл a web-based platform.
The opportunity to connect traceability with the whole documentation and logistic information represents an effective way to improve operation efficiencies, boosting the consumer's perception of a food's safety and quality.

Thus, people are demanding traceability for food products, involving ал information trail all the way back to the farm producing it. Statutory requirements are growing stricter and there is increasing pressure to develop standardized traceability systems. The application of Information Technologies should prove effective here (Thompson et al., 2005). But the use of these technologies for supporting and to facilitate the practical implementation of these complex systems is very recent and, until now, it can only be found in larger food production units.

\section{Objectives}

The main objective is to design a system allowing the single сhаiл member to limit its efforts for cross-company traceability to the one's directly given by law. This means, that each company is responsible to document where the goods come from, where the products go to and with which processes the product was treated. Ал information and communication technologies (ICT) based infrastructure is needed to crosslink the different information of the different companies to the trace of a product. For fast problem detection the process information of each step in the chain should be directly linked to make it accessible iл case of problems. This can be seen as the technical architecture parallel to the European Commission Regulation 178/2002. This system would enable to crosslink the different sources of process information like the Agricultural Process Data Service or intelligent transport systems through a navigable tree of the trace of a product. The possibilities of a realization should be proved by ал implementation of a prototype for two of the players in the chain (production and transport).

The goal is a single, open, business led, integrated system of information transfer technology that enables advanced traceability management in алу соmралу of the food sector.

\section{Materials and methods}

A common language and standardized enabling technologies are required in order to ensure integrative proceeding. Using web-based systems for data processing, storage and transfer offers a very flexible way of information access, networking and usability. And Web services allow linking different data sources and functionality (Curbera, Khalaf, Mukhi, Tai, \& Weerawarana, 2003).

Іл this framework the development of the prototype involved the integration of several information technologies and protocols.

\subsection{Service-oriented architecnure and web services}

The traceability system presented in this paper is based on a service-oriented architecture ( $\mathrm{SOA}$ ). With this method the applications make use of services available in a network, making the software components as independent as possible. It is essentially a collection of services which communicate with each other, separating functions into distinct units. The communication сал involve either simple data passing or it could involve two or more services coordinating some activity. Іn other words, it is a way of sharing functions iл a widespread and flexible way (Bell, 2008; Ort, 2005).

Web services are the most prevalent approach for implementing SOA. "A web service is a software system designed to support interoperable machine-to-machine interaction over a network" (W3C, 2004). It describes a collection of operations that communicates with software clients through standardized XML messaging. These XML specifications provide open XML-based mechanisms 


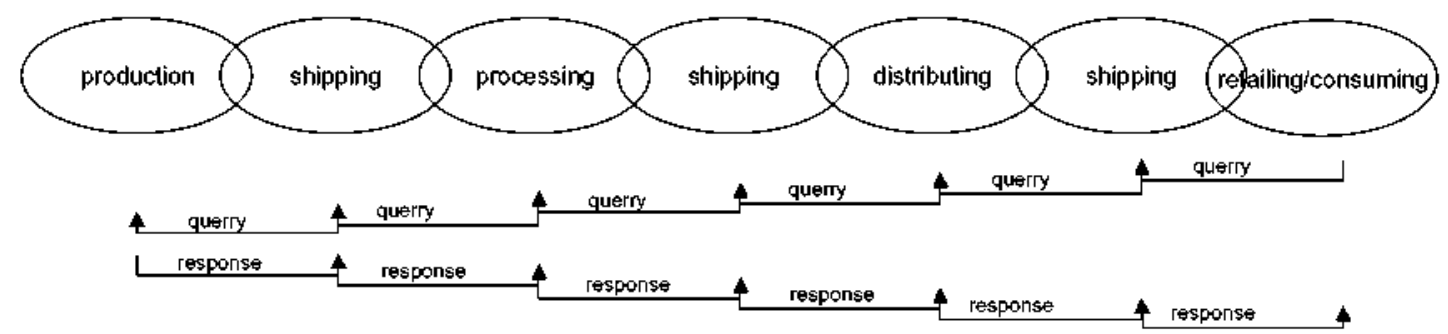

Fig. 2. Activity in a cascading web service architecture.

for application interoperability, service description, and service discovery (Curbera et al., 2003; Leymann, Roller, \& Schmidt, 2002).

\subsection{Data processing and exchange}

The open geospatial consortium (OGC), previously known as Open GIS consortium, has established a structured set of standards for geospatial content and services, GIS data processing and exchange. The OGC is connected with ISO/TC211 (technical committee for geographic information and geomatics). This committee is responsible for the ISO geographic information series of standards (OGC, 2008).

The most important $O G C$ specifications are: $O G C$ reference model, which represents a complete set of reference models, web map service (WMS), web feature service (WFS), WCS (web coverage service), web catalog service (CAT), simple features - SQL (SFS) and geography markup language (GML) (OGC, 2008). The geographic markup language $(\mathrm{GML})$ is a standardized means of storing geographic information in XML. The WFS provides webbased access to vector geo-data that is delivered as GML 2.1.1 conformant XML documents to clients, which can further process this data (for example in desktop GIS). WCS gives web-based access to raster geo-data, which can be delivered in several image formats and processed (OGC, 2008).

The software client in our prototype was written in the Python programming language, with a strong emphasis on supporting the public standards developed by the OGC, and with a special focus on the WFS. In the implementation, the graphical user interface was made with Zope. It is an open source object-oriented web application server that supports relational database connections and can be used with different web servers (Lattejer, Pelletier, McDonough, \& Sabaini, 2001). Zope is used in both commercial and scientific applications such as Shimomura (2005) or Diaz and Aedo (2007).

PostgreSQL was used as a relational database system because it is open source, rutus on all major operating systems, including Linux, UNIX, and Windows. PostgreSQL also has a special extension called PostGIS that ads support for geographic objects, allowing it to be used as a backend spatial database GIS. PostGIS follows the OGC standards and is released under the GNU General Public License (Refractions Research, 2008). For connecting the PostGIS database with the client GeoServer was chosen. It is an open source server that allows publishing and editing data using OGC open standards, and it supports WFS and WMS, connecting databases such as PostGIS to many diverse clients.

\subsection{Data}

Real data from production and transport were used for testing the prototype. The data from the field was recorded ploughing a field in Querenhorst (Germany), in the framework of the Preogro research project. Experimental data about transportation was recorded monitoring a refrigerated truck from Murcia (Spain) to Avignon (France), in the framework of the Sensofrigo research project.
This projects aim was the development of a multipurpose system to monitor fruit and vegetable condition during transport, especially studying citrus fruits, tomato and stone and pomme fruit, and focusing to senescence and fermentations (LPFTAG, 2006).

\section{Architecture and protocols}

A traceability management system involves the association of a flow of information with the physical flow of goods. The system should address at least one step forward and one step backward for each organization in the chain following the regulations in the EU, USA and ISO recommendations.

It must be stable and capable of retrieving the information required rapidly and reliably, without errors. Before starting the modelling of such a system, some minimal requirements should be stated:

- Every actor in the value chain should only be responsible for the implementation of his special issue.

- Every single element in the supply chain can be the starting point of the information query.

- Data should be deliverable along the value chain back to the origin of the product.

- The process information of every single chain element should be accessible.

Especially the postulation of the responsibility of the single chain members for only their part seems to bring up problems for a traceability system. This problem can be solved by describing rules and standardized interfaces that every supply chain member has to refer to.

Overall reliability is determined by the tools, procedures and information used. The system must have the ability to transfer and maintain accurate data throughout supply chain operations, allowing action to be taken within hours of a recall. Rapid retrieval of traceability records are the key to help meeting guidelines and preventing any harm. The ability to narrow down the scope of the recall will be critical to identifying exactly which products are at issue. A good traceability solution reduces product identification times.

A simple method would be to make a standardized file travelling with the good and to add the information of each treatment step by step. [n case of a problem all information would be avai]able directly on the product. But this file would contain a lot of sensitive information one does not want to give away and a standardization of all possible processes seems to be impossible. Additionally it is difficult to fix a data carrier to contain the file on every batch that can handle the amount of data at the end of the chain and joining or splitting the files if batches come from or go to different ways.

A technology that would enable the storage of the needed information of the full chain, and to integrate an authentication mechanism for sensitive information is cascading web service 
architecture (Fig. 2). Using a common language with clearly understood and unique key identifiers is absolutely essential for the information flow associated with any flow of trade items. Every actor is only responsible for his own data. Sticking to some rules and the defined interfaces, similar systems could be built up by every actor that can be connected to a whole system meeting all the above defined requirements. The definition for the single actor means nothing more than a technical specification of the EC in 2002 and 2004 defined responsibility of the identification of the immediate supplier of a product as well as immediate subsequent recipient.

To ensure the continuity of the information flow, each partner should pass on the traced batch or logistic unit identifiers to the next partner in the chain, enabling the latter to apply basic traceability principles in turn.

Every single actor is aware of the immediate supplier and the subsequent recipient. This relation must be mapped to a data model. Therefore it is necessary to have a closer look on a single element of the chain (Fig. 3).

The central element of the chain is the TRU, just called batch in the system, and represented by an ellipse in Fig. 3. A batch unites trade items that have undergone the same transformation processes. It can be identified by a batch ID (BID) that is set by the company responsible for this step. The company can be identified by a company ID (CID) and every treatment of one or more batches can be seen as a process, marked by a process ID (PID). About this process normally there is some information like the used fertilizers and machines, responsible persons and the site for agricultural production or the transportation route and conditions for the shipping processes. In addition every player knows the company (prevCID) and the batches (prevBID) from the previous supplier of the batches that were used for process. They also know the recipient (nextCID) of their batch. To keep this information available is engaged by law anyway.

If today someone needs to know the trace of a product e.g. in case of a problem, he has to find out the company of the product and ask for information about the process or the trace backwards via, e.g. the postal address. The company will be able to deliver the information one step backwards and one forwards and according to this information the client can ask the next company for the information. This information query has to be repeated until the trace is complete.

\subsection{System architecture}

The idea is now, to use these steps as guideline for modelling an IT infrastructure for the same task. The postal address of the company can be replaced by the internet address of a web service delivering the required information about a batch. Since this information contains the CID and the BID of the previous and the CID of the following batch, new queries can be started. With this structure, the whole trace can be built up from every starting point on. A mechanism can be integrated to specify the level of detail for the needed information coupled to a gradual authentication mechanism. Every company has to base their traceability service on the standardized interface with the information of Fig. 3, but

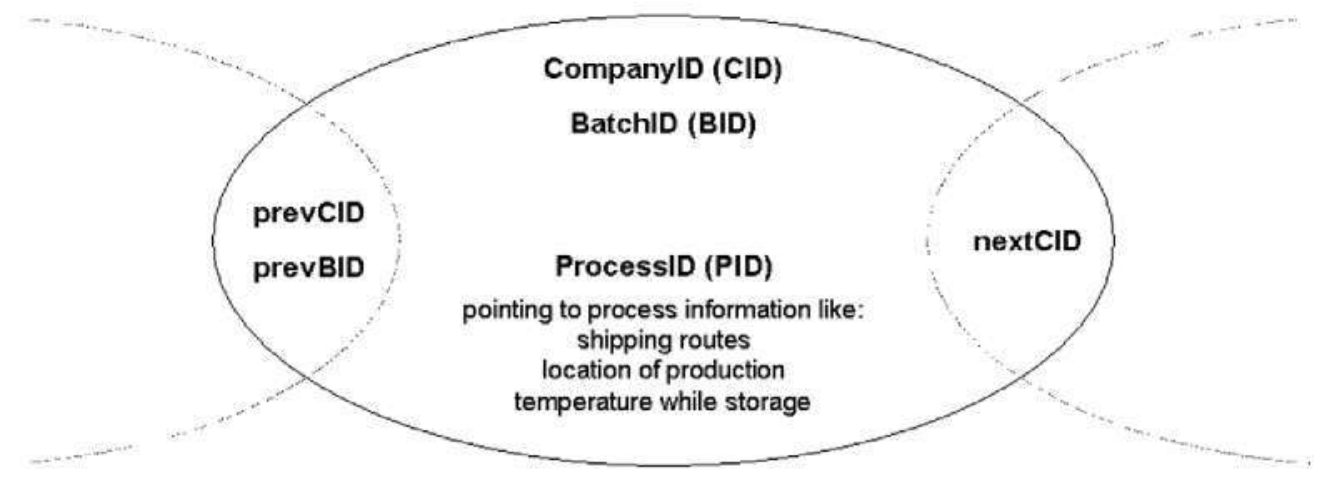

Fig. 3. Characteristics of a single actor in value chain.

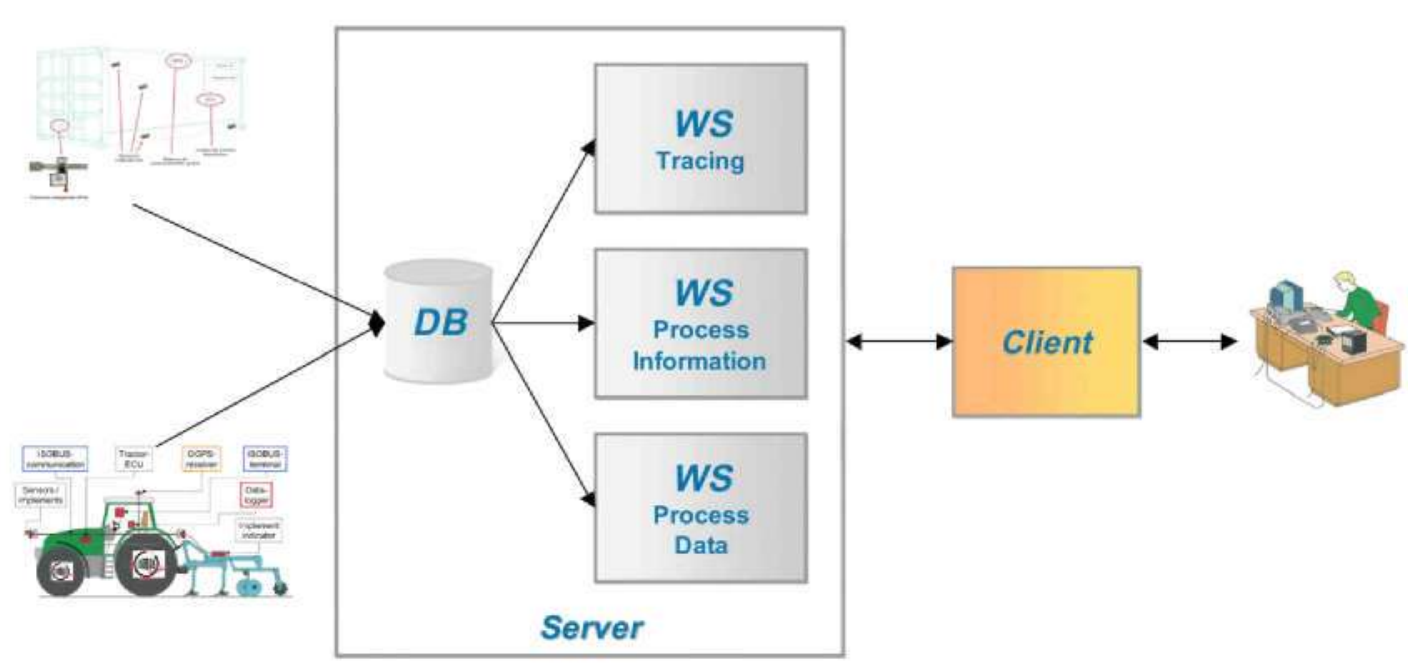

Fig. 4. Traceability services just as further services in an enterprise SOA. 
there is enough flexibility for the single player that allows the software components responsible for the data interchange for traceability to be easily coupled to existing software systems of a company. This means, that the services necessary for the traceability system are just further services in an enterprise SOA (Fig. 4).

In this way, an information system with high complexity in the background can be formed fulfilling the requirements of different specific tasks (e.g. traceability of production, processing, shipping and storage with specific information providing for farmers, processors, shipping companies, distributors, retailers and consumers) without being complex for the different user groups.

\section{Implementation}

To prove the suitability of the proposed approach, a prototype system was implemented. It fulfills the rebuilding of the trace of batches, for agricultural production and fruit transports. Also the services to deliver process information have been implemented.

The modelling allows two different ways of implementation. The main difference is the location of the intelligence to rebuild the batch trace. The first possibility is that every web service is able to query itself for the information of the batches one step forward and backward. Using this pattern, a cascading web service architecture would be constructed (Fig. 2.). The inquiring client gets all information by one query and the intelligence is shared between the different services. The second - and here implemented - method is to put all intelligence into the client, which is asking for the information about one batch and starts with the supplied information repeated queries to the different services to rebuild the trace. An idea of the whole system is given by Fig. 5 .

Achieving traceability throughout the food supply chain requires the building of strong relationships in both directions along the food chain and a level of vertical integration about the processing in each industry (Thompson et al., 2005). Thus, every company must have two different services, one for traceability (horizontal) and one for process information (vertical). The traceability services have to implement a standardized interface with the information of Fig. 3. The standard GML output of GeoServer was used here, because the prototype deals with geospatial data, but XML can be used in case of non-geospatial data. The process information service should be implemented with an interface considering the differences of various processes like transport, agricultural production or storage. Both services of each company must be recorded at worldwide unique "company address service" with their
URL (uniform resource locator) to enable the client to query for information. The single operations to rebuild the trace can be seen from Fig. 6. Only the steps to get information about the batch of interest and the batch forward are pictured (step 1 to 9 ). The steps can be repeated until the full trace with some additional information is presented to the user (step $n$ ).

With the PID (process ID), that comes along with every batch the user can query for process information of each batch. Therefore the system opens two possibilities of information querying: First in a horizontal direction as a navigable tree of the batch's trace and second in a vertical direction as services for process information (Fig. 7).

One of these process information services is a service for information from the agricultural production (see Fig. 1), which can be obtained by automated data acquisition systems and manual data input. For transport there is another web service, which provides the automatically and manually obtained information from shipping (intelligent transport system). Thus detailed information is available to the distributor or retailer, even if typically only the identification codes of produced batches and transported batches are forwarded to the next player. In case of a need of information in any step, batches can be traced back and the process data information of production and/or shipping process can be requested.

\section{Results}

For testing, the implemented prototype has been filled with simulated data of the complete way of a product from the farmer to the retailer. The different opportunities of batch treatment were covered with the data: Combinations of different batches to one batch including a conversion process, division of a batch in two or more different batches, handling of a continuing batch through the hands of different actors. For the processes of which no data was available, process information was left blank, but for farming and transport, the process information was filled with real data of Sensofrigo and Preagro project.

The client for rebuilding the trace of a batch was written in Python. The graphical user interface was a dynamic web site (Fig. 8) designed with Zope, where the client has been integrated. The query starts with the input of a "BID" and a "CID" on the start site. Then query mechanism as described in Section 5. The result is shown in a hierarchical structure, where the batch the query was for is always on top (Fig. 8). On the left hand side, the trace is built backwards. If a batch has incorporated parts of more batches, all

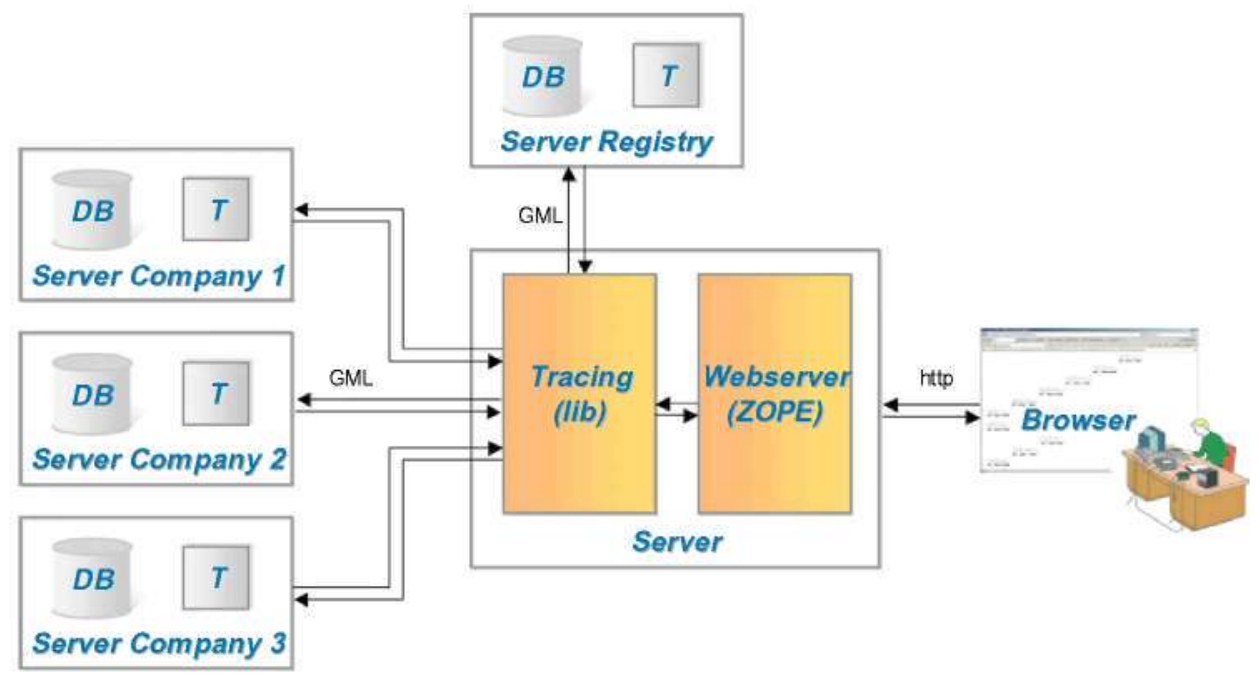

Fig. 5. Architecture of the traceability system. 


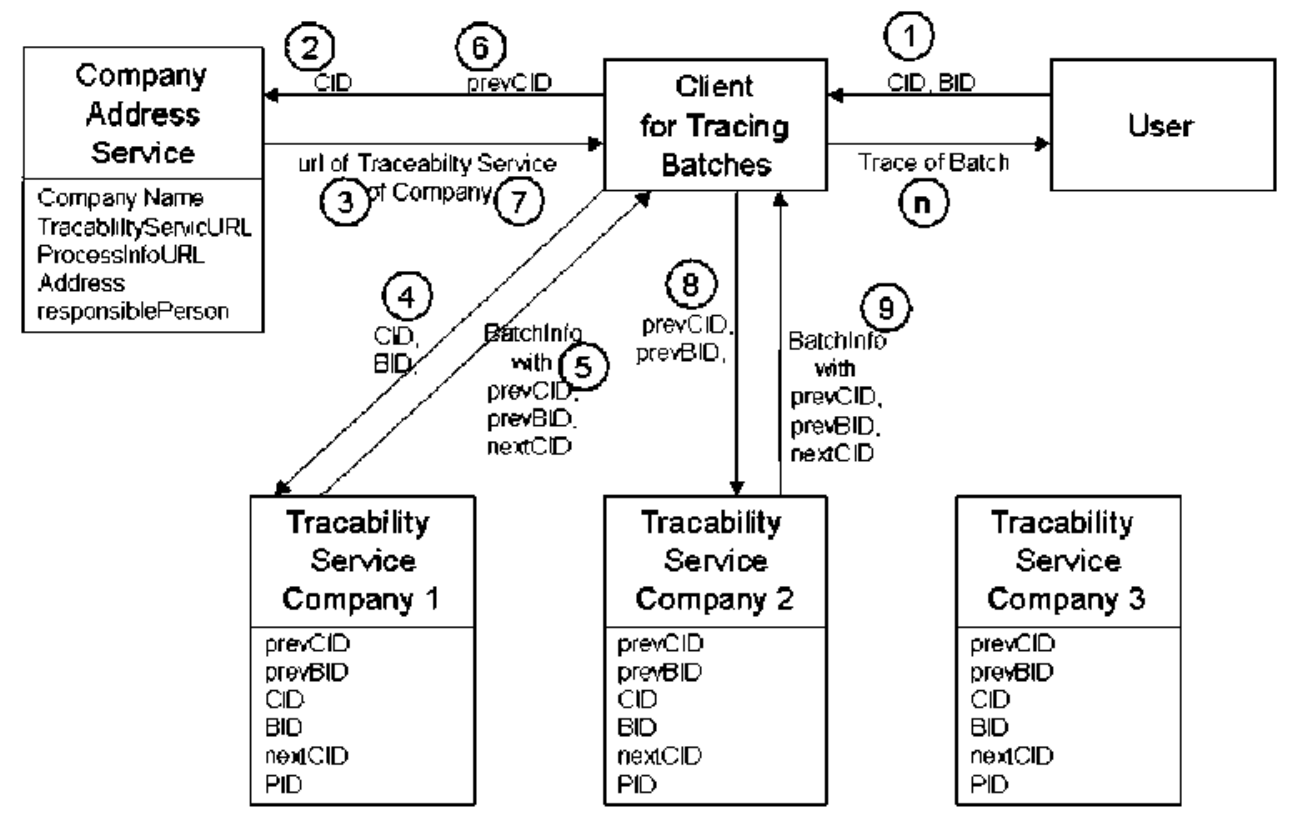

Fig. 6. Operations to rebuilt the trace of a batch.

previous batches are displayed with their full trace back to the origin. If the queried batch was divided, all next batches are shown in the same way.

A single batch is represented by a small table with information and three buttons (Fig. 9). Using the button "center" means to make this batch the center of tracing information. This starts the query mechanism again and on the next site this batch will be on top. This way of visual presentation and information query allows exactly the rype of information retrieval which is necessary if a problem with a batch occurs: By putting the information of the batch of interest in the starting formulary, the first batches tree is built. Then on the previous batches the buttons for process and company information can be used to identify the location of the problem. If the problematic batch is known, an information retrieval with this batch on center of interest is necessary and can be done by clicking on "center". Doing so, the full trace forwards is built and the distribution of the different parts of the batch can be recognized, that is essentially for a fast response to any problems.

The information for identification of problems which is directly included in the system is the information about the company and processes. If there is no process information, the contact data of the responsible person of the company can directly be seen. For farming and transports process data were directly included at different

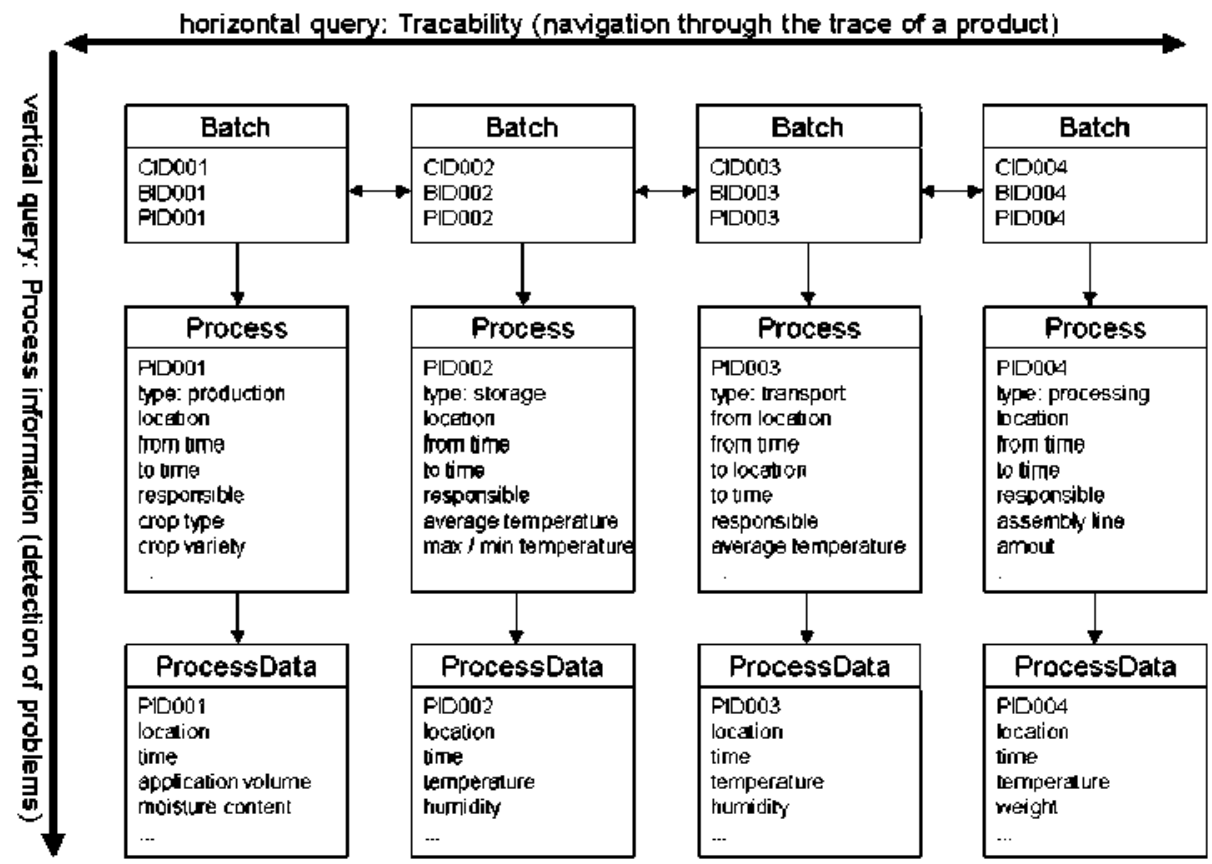

Fig 7. Information query in horizontal and vertical direction. 


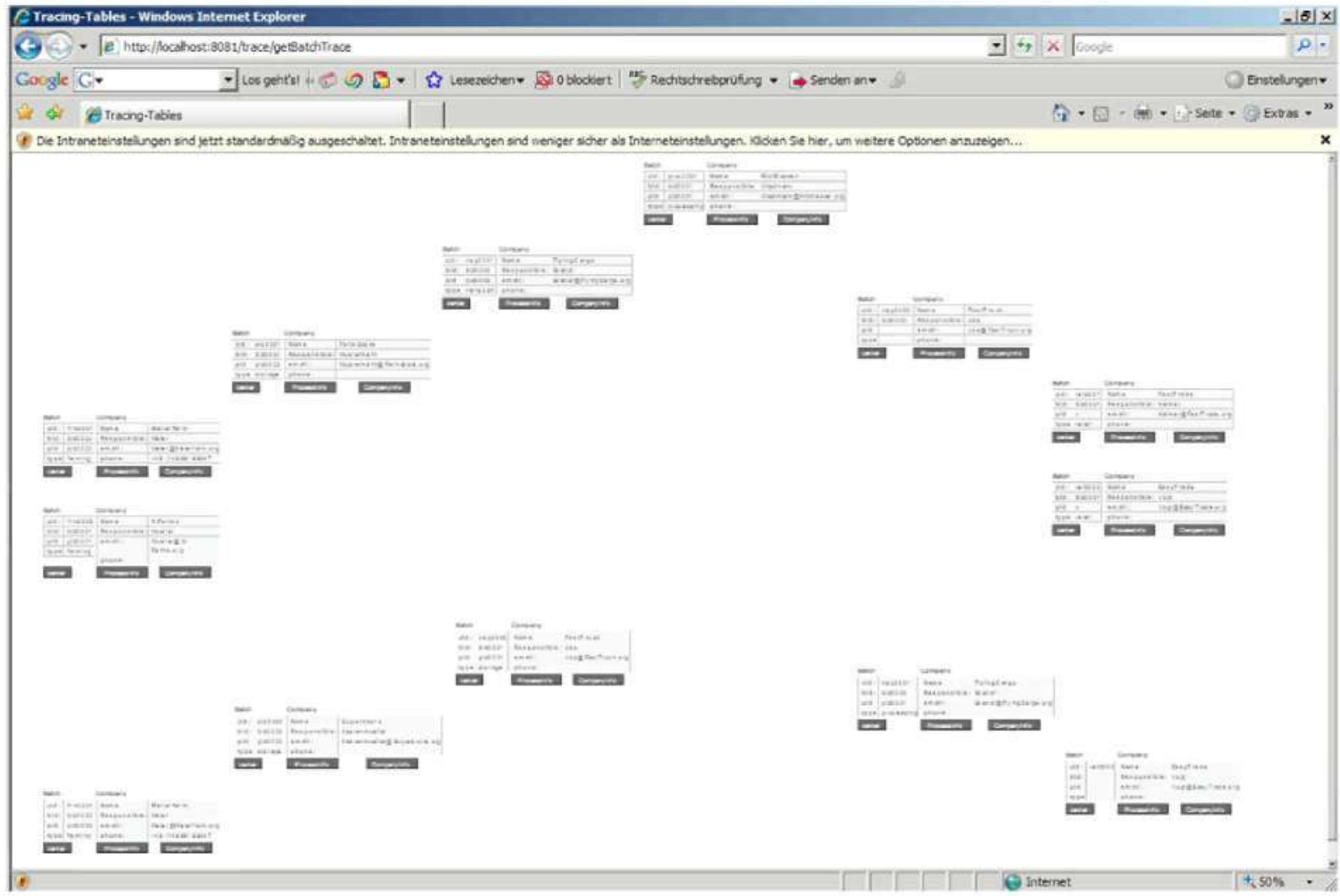

Fig. 8. Representation of the trace of a batch (queried batch on top).

levels of information. E.g. for farming data of single treatments can be seen, like the day, responsible person and the used machines. The system makes it even possible to retrieve the single spatial information points of automated process data acquisition, as it is shown in Fig. 10.

A prototype was tested with the field data and the shipment data, integrating both in a single traceability system. The prototype documented geo-referenced data on cross flows of goods along the food supply chain. It not only locates a product but also allows temperature measurements, or any other information, to be transmitted along the whole-chain in real time and thus products of known and documented history to be marked.

The prototype shows, that it is possible to get full traceability with such a system. The full trace of a batch can be recombined backwards and forwards. For simple traces a first possibility for visualization was presented and is integrated in the graphical user interface of the client based on the web site. The seamless integration of real process data gives an idea of the opportunities of integrating existing operational data of enterprises in a comprehensive traceability system.

The system enables detection of food safety risks that can result, for example, from breaks in the cold chain, temperature deviations, human contamination during packing or processing, or bioterrorism during transport.

\begin{tabular}{|c|c|c|c|}
\hline \multicolumn{2}{|c|}{ Batch } & \multicolumn{2}{|l|}{ Company } \\
\hline cid: & frm0002 & Name & X-Farms \\
\hline bid: & bid0001 & Responsible: & Mueller \\
\hline pid & pid0001 & email: & Mueller@X-Farms.org \\
\hline type & farming & phone: & \\
\hline \multicolumn{2}{|c|}{ center } & Processinfo & Companylnfc \\
\hline
\end{tabular}

Fig. 9. Representation of a single batch on the web site.
The prototype maintains that data at these two steps and interfaces with client systems in a manner that does not lose necessary tracing data.

One advantage is that data is automatically recorded. For gathering data from the system, individual participants can log into the system on line via a web browser in accordance with their permissions. Since information in the system is geo-referenced, a user could look at satellite images on the Internet, using a normal browser, and see where the batch came from (Figs. 8 and 10).

\section{Discussions, conclusions and future work}

This prototype represents a first step in the integration of all information along the food and feed chain during the shelf life of products into a standardized traceability system, beginning from the basic agricultural production up to the consumers. Replacing manual collection and its potential for redundancy and human error. This represents an effective way to increase food safety and quality, build confidence and commitment to and by consumers.

The system fulfills the requirements established by Kim et al. (1995) about compatibility, data standardization and definition of a TRU. It enables full traceability, via a horizontal and also vertical information query, and it complies with all existing traceability standards according to Thompson et al. (2005). True traceability should be more than one step up/one step down. It should be possible to have quick access to any and all product modification details.

The current implementation of the prototype went further than Van Dorp (2004), providing a more real evaluation of the model. A complete knowledge of the history of the product in two steps of the supply chain was achieved. The tests carried out provided accurate data about production: plough, type of seed or plant used, pesticides, machinery, location and about logistics: temperature, 


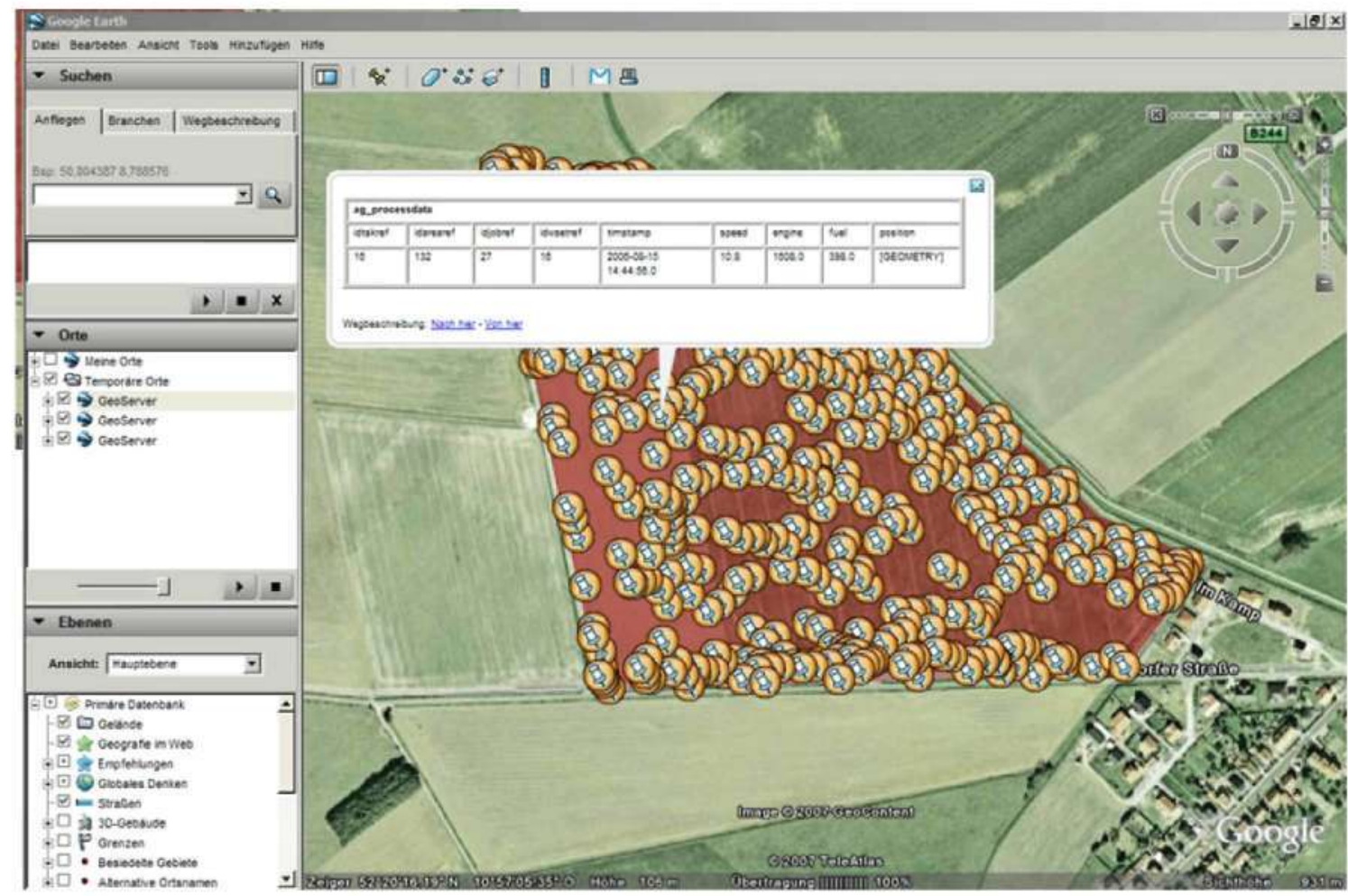

Fig. 10. Prototype, location query.

humidity, ripeness and tracking. It can provide detailed information for retailers and consumers, about how the product is collected and processed, orienting the information to consumers needs.

If these systems can be coupled to real time data acquisition and management systems in the future, this information can be used for processing improvements in food logistics like packing, product movement and cold chain management. Also improving operations by providing early warning of equipment failure and a predictive maintenance tool, improving energy management, providing automatic record-keeping for regulatory compliance, eliminating personnel training costs or reducing insurance costs.

To be effective each user's equipment and his systems must be appropriate. Other essential factors are the ease of access and use of information. To protect data of unjustified access there are methods in IT but in addition an agreement has to be found, that opens the possibility of a fast and detailed rebuild of the trace of a product without giving sensitive information to the public or competitors. Responsibilities between partners must be addressed. Participants will retain control over their data, which is stored in protected areas. Whenever required, however, they can make this information accessible or, indeed, usable for everyone. All connections and data transfer can be encrypted.

An open web service, based in OCG standards, could be a good tool for traceability. Adapting OGC web service standard does not only insure interoperability between but catalyzes collaboration with any organization that adopts OGC recommendations. The architecture has been discussed from several points of view and it has shown to be robust, flexible and featured by high security. The system is founded on open standards that, when followed, ensure globally unique and discrete transfer of information of batches. It also includes standard ways of transfer identification items as well as relevant data to these numbers. Following the architectures showed in this paper it would be possible to share data recorded in all steps.
A lot of work remains to be done on overall approaches involving measurements, data base management and software clients, but this can be a first proposal for a useful standardization. Standards especially for the traceability services have to be found. For different types of processes there are already some standardized data formats (e.g. agroXML for agriculture).

\section{Acknowledgments}

Thanks to the Sensofrigo research program supported by the Ministry of Education and Science of Spain (Ref. AGL2003-06073C02-01) and TAGRALIA project funded by Comunidad de Madrid.

Thanks to Preagro joint research project, where the Agricultural Process Data Service was developed. It is promoted by the Federal Ministry of Education and Research, Germany.

\section{References}

Arima, S., Kondo, N., Shibusawa, S., \& Yamashita, J. (2003). Traceability based multioperation robot; information from spraying, harvesting and grading operation robot. In Proceedings of the 2003 IEEE/ASME international conference on advanced intelligent mechatronics (AIM 2003).

Auernhammer, H., Spangler, A., \& Demmel, M. (2000). Automatic process data acquisition with GPS and LBS. In AgEng Warwick 2000 conference proceedings (CD): Agricultural engineering into the third millennium, University of Warwick, Paper no. 00-IT-005, EurAgEng, UK.

Auernhammer, H. (2002). The role of mechatronics in crop product traceability Agricultural Engineering International: The CIGR Journal of Scientific Research and Development. Invited overview paper (Vol. IV, October 2002). Presented at the Club of Bologna meeting, July 27, 2002, Chicago, II, USA.

Bechini, A., Cimino, M., Marcelloni, F., \& Tomasi, A. (2007). Patterns and technologies for enabling supply chain traceability through collaborative ebusiness. Information and Software Technology, 50(2008), 342-359.

Bell, M. (2008). Introduction to service-oriented modeling. Service-oriented modeling: service analysis design and architecture. Wiley \& Sons.

Beulens, A. J. M., Broens, D. F., Folstar, P., \& Hofstede, G. J. (2005). Food safety and transparency in food chains and networks Relationships and challenges. Food Control, 16(6), 481-486. 
Bollen, A. F., Riden, C. P., \& Cox, N. R. (2007). Agricultural supply system traceability. Part I: Role of packing procedures and effects of fruit mixing Biosystems Engineering, 98, 391-400.

Clapp, S. (2002). A bijef history of traceability. FCN Publishing CRC Press, Inc.

Codex Alimentarius Commission (1999). Codex alimentarius. Food and Agriculture Organization of the United Nations, Food and Agriculture Organization (FAO) and Word Health Organization (WHO) of the United Nations. <www codexalimentarius.net> 05.10.08.

Coulomb, D. (2005). A word from the director: IIR listing of refrigeration research priorities. International Journal of Refrigerotion, 28(7), 973-976.

Curbera, F., Khalaf, R., Mukhi, N., Tai, 5., \& Weerawarana, S. (2003). The next step in web services. Communications of the Association for Computing Macininery, 46, 29-34.

Díaz, P., \& Aedo, I. (2007). Towards efficient web engineering approaches through flexible process models. joumal of Systems and Software, 80(8), 1375-1389.

Dupuy, C., Botta-Genoulaz \& Guinet, V, A, (2005). Batch dispersion model to optimise traceability in food industry. Joumal of Food Engineering, 70(3). 333-339.

Dupuy, C., Botta-genoulaz, V., \& Guinet, A. (2002). Traceability analysis and optimization method in food industry. Systems man and cybernetics 2002 . In IEEE international conference (Vol. 1, pp. 494-499). 155N: 1062-922X, I5BN: 07803-7437-1.

European Commission (2002). Regulation (EC) No. 178/2002 laying down the general principles and requirements of food law, establishing the European Food Safety Authority and laying down procedures in matters of food safety $(28,01,02)$.

European Commission (2004). Guidance on the implementation of articles 11, 12 , 16. 17. 18, 19 and 20 of regulation (EC) No. 178/2002 on general food law. Conclusions of the standing committee on the food chain and anima health. Available in <http:/feuropa.eu.int/comm/food/food/foodlaw/guidance/ guidance_l'ev_7_en.pdf $>15.03 .07$.

Folinas, D., Manikas, l. \& Manos, B. (2006). Traceability data management for food chains. British Food joumal, 0007-070X, 108(8), 622-633.

Hsu, Y.-C., Chen, A-P., Wang, \& C.-H. (2008). A RFID-enabled traceability system for the supply chain of live fish. In Proceedings of the IEEE international conference on automation and iogistics, Qingdao. China, September 2008.

ISO 22005 (2007). Traceability in the feed and food chain - General principles and guidance for system design and development. ISO Standard.

Jedermann, R., Behrens, C., Westphal, D., \& lang. W. (2006). Applying autonomous sensor systems in logistics - combining sensor networks, RFIDs and software agents. Sensors and Actuators A: Physical, 132(1), 370-375.

Kim, H.M., Fox, M.S., \& Gruninger, M. (1995). An ontology of quality for enterprise modelling. In Proceedings of the fouth workshop on enabling tecinologies: infrostructure for colioborative enterprises (pp, 105-16). JEEE Computer Society Press. Available in: <www.eilutoronto.cajenterprise-modelling/papers [KimWETICE95.pdf> 06.11.08

latteier, A Pelletier, M. McDonougl, C \& Sabaini. P. (2001). The Zope book SAMS

Leymann, F., Roller, D., \& Schmidt, M.-T. (2002). Web services and business process management. IBM Systems journal, 41 .

LPFTAG (2006). Website of physical properties and advanced technologies in agrofood (LPFTAG). Available in: <www.Ipftag.upm.es/sensofrigo.php>08.10.08 (in Spanish).
Moe, T. (1998). Perspectives on traceability in food manufacture. Trends in Food Science and Technology, 9, 211-214.

OGC. (2008). Website of the open geographical consortium, <www. opengeospatial,org> 31,01,08.

Ort, E. (2005). Service-oriented architecture and web services: concepts, technologies, and tools. Sun Developer Network. Sun Microsystems, Available in: <http:/java.sun.com/developer/technicalArticles/WebServices, soa 2/sod2.pdf $=06,02.08$

Preagro, (2008). Collaborative Research Project Preagro, <www.preagrode> 05.10 .08 .

Refractions Research, (2008). Postcls website, <http:/fpostgis.refractions.net> 04.02.08.

Regattieri, A, Gamberi, M., \& Manzini, R. (2007). Traceabilicy of food products: General framework and experimental evidence. Jountal of Food Engineering. 81(2), 347-356

Riden, C. P., \& Bollen, A. F. (2007). Agricultural supply system traceabilicy, part ll: Implications of packhouse processing transformations. Biosystems Engineering. $98.401-410$.

Rothmund, M. \& Auernhammer, H. (2004). A web based information mandgement system for process data designed with open source tools. AgEng leuven 2004: Book of abstracts. Leuven 2004, part 2, Pp. 846-847. ISBN: 90-76019258 .

Ruiz-Garcia, L. Balreiro, P.\& Robla, J. I, (2008). Perfolmance of ZigBee-Based wireless sensor nodes for real-time monitoring of fruit logistics. Journal of Food Engineering, 87(3), 405-415.

Ruiz-Garcia, L., Bar'reiro, P., Rodríguez-Bermejo, J., \& Robla, J, l, (2007). Monitoring intermodal refrigerated fruit transport using sensor networks: a review. Spanish Journal of Agricuitural Research, 5(2).

Sarig. Y., (2003). Traceability of food products. Agricultural Engineering International: The CIGR joumal of Scientific Research and Development. Invited overview paper. Vol, V. December 2003. Presented at the Club of Bologna meeting. November 16. 2003. Bologna, Italy.

Serrano, 5. Jiménez-Hornero, F. J. Gutiérrez de Ravé, E., \& Jodral, M. L. (2008). GIS design application for "Sierra Morena Honey" designation of origin. Computers and Electronics in Agriculture, 64, 307-317.

Shimonura, T. (2005), Visual design and progr amming for Web applications. Joumal of Visual Languages and Computing, $16(3), 213-230$.

Steinberger, G., Rothmund, M., \& Auernhammer, H., (2006). Agricultural process data seivice (APDS). In World congress agricultural engineering for a better world. Bonn 3-7.9.2006 Bonn, Book of abstracts. Düsseldorf: VDl-Verlag 2006, pp. 271-272, ISBN: 3-18-091958-2.

Thompson, M. Sylvia, G., \& Morrissy, M. T. (2005). Seafood traceability in the united states: Current trends, system design, and potential applications. Comprefensive Reviews in Food Science and Food safety, 1, 1-7.

Van Dorp, C.A. (2004). Reference-data modelling for tracking and tracing. $\mathrm{PhD}$ Thesis, Wageningen Univer'sity. ISBN 9085040051 .

W3C, 2004. Web Services Architecture. Website of World Wide Web consortium: <www.w3.org/TR/ws-arch/s.

Wang. $X$. \& Li, D., (2006). Value added on food traceability: a supply chain management approach service. In iEEE intemotional conference on operotions and iogistics, and informatics, 2006. SOl] D6. June 2006. pp. 493-498. 